but, despite the very long hours put in each day, there was insufficient time for adequate and fruitful discussions.

The main discussion at the two symposia, at which Prof. Marini-Bettolo (Italy) presided, centred around the papers of Drs. Hais and Macek, and included contributions by Drs. Consden, Smith, Waldi, Racinskij and others. They emphasized the fact that the vast amount of chromatographic data in the literature was not being used to the full simply because of the lack of standardization of apparatus, methods, reagents, etc., and that this rendered. comparisons and deductions between the results of different workers dangerous. They directed attention to the very wide and detailed systematic studies of Dr. I. Smith in the biochemical field and to the limited number of such studies in other fields. We were interested to learn that the Soviet Union does not produce a single piece of apparatus which is primarily intended for paper chromatography. The variety of types of apparatus used by workers in different countries is unfortunately manifold. Because of these differences it is not yet possible to correlate the data produced in different laboratories on anything like the scale which would be desirable. This is regrettable, as there can be no doubt that standardized and correlated data would be valuable in avoiding the present duplication and reduplication of labour. Moreover, far more important than this, standardized data could be used on electronic data processing machines based on suitable punched-card systems. Furthermore, the availability of such standardized. data would be valuable for the determination of various other chromatographic data, such as $R_{m}$ values, and for the correlation of such properties with other physicochemical measurements. This in turn might lead to a type of structural analysis based on the splitting of $R_{F}$ and $R_{m}$ values into functional group constants with the possible application of physical-organic chemistry to the general problems of paper chromatography. This latter point was discussed at some length by Ing. Prochazka and Ing. Gasparic. The Czech Chemical Society has attempted with some success to standardize methods in its own country and, in spite of difficulties, Drs. Macek and Hais have gone ahead and devised their own punched-card system suitable for machine operation. No doubt we can look forward to more interesting developments from their laboratories.

Participants were shown around two laboratories. Dr. Macek conducted a tour of the Pharmaceutical and Biochemical Research Institute, which is well equipped to study all aspects of paper chromatography, including the data-correlation problem. This was followed by a tour of the Institute of Organic Chemistry and Biochemistry of the Czechoslovak Academy of Science, led by Prof. B. Keil. The main problem of Dr. Keil and his team is the amino-acid sequence of chymotrypsinogen and the laboratory is extremely well equipped for this purpose. The electronic data sorting approach to the study of overlaping sequences, etc., is also in an advanced stage. We are interested to note the close collaboration between this team and others in the United States working on the same problems. I. SMITH

J. B. WEISS

\title{
FOREST PRODUCTS RESEARCH IN BRITAIN
}

\begin{abstract}
HE extreme complexity of the principal product of the forest, timber, is well exemplified by the very varied contents of the report for 1960 of the Director of Forest Products Research*. In it reference is made to research into wood structure, wood seasoning, bending, mechanics and other properties of timber. Sections are devoted to woodworking, wood preservation and to the study of the fungi and insects which batten on timber. The chemistry and physics of timber are receiving attention and in this connexion surely more attention should be given to the chemistry of those timbers of trees which from a sylvicultural point of view ought to be much more widely grown, especially in England, than they are-namely, oak, birch, alder and other leaf-trees. It would be very helpful if timbers containing substances which are a nuisance in paper-making, but which might furnish materials for other uses, could be enhanced in value and grown more profitably. Recent progress in Japan is of interest.

The close association of the Forest Products Research Laboratory with the Forestry Commission no doubt accounts for the prominence given in the research programme to Sitka spruce and what is loosely called "Lodgepole pine". The former has been very extensively planted and the latter, after a period of neglect, is now also much in favour. Both are useful trees, and it is certainly important that

* Department of Scientific and Industrial Research. Forest Products Research 1960: Report of the Products Research Steering Committee with the Report of the Director of Forest Products Research. Pp.
$\mathrm{v}+60+8$ plates. (London: H.M.S.O., 1961.) 58. net.
\end{abstract}

everything should be done to justify their being grown, but surely not at the expense of work on other sylviculturally more useful trees with no less valuable timber. The Republic of Ireland, where the utility of Pinus contorta Doug. was appreciated earlier than in Great Britain, is indeed fortunate in being able to make use of the Laboratory, while the latter is fortunate in being able to obtain research material from abroad suited to its needs.

An investigation just completed into the strength and specific gravity of Sitka spruce grown in Great Britain proves fairly conclusively that the method of site classification adopted by the Forestry Commission is at fault. The samples tested were chosen from six geographical regions corresponding to 'Districts' of the Meteorological Office, in other words, climatic regions, and within these the stands of trees, whence the samples came, were classified into five groups based on rate of growth in height, called, unfortunately, quality-classes, but really productivity-classes. The interesting result of this investigation was to find no significant differences among the six climatic regions, nor among the productivity-classes as a whole, but that differences in quality tend to arise more from individual site factors. It thus seems that rate of growth is not a sound basis of site classification for this kind of work, as most foresters realize. A better classification is one based on the factors of geology and the availability to the trees of nutrients and soil moisture. It would be valuable to have the work repeated or the existing data re-analysed on such a basis. 
The report does not say specifically what the value of the timber of Pinus contorta Doug. is compared with that of other trees, information which would be of the utmost importance to the forester. The structure of its wood is said to be intermediate between, for example, yellow pine and Scots pine. There is some slackness in nomenclature in the report; apart from leaving one in doubt about what yellow pine is, the terms 'redwood' and 'whitewood' are still used with no explanation that the former is wood of Scots pine and the latter that of Norway spruce. The laboratory should think of the grower as well as of the user.
It is almost certain that timbers will long remain among the most useful of raw materials, and the more we can learn about them the better. As the chairman of the Forest Products Research Steering Committee in his introduction says, there is no lack of work to be done, but why is all the work kept in the south of Britain ? Some could be done just as well at a properly equipped laboratory in the north. The Committee has a difficult task in avoiding the many reefs and in selecting the most profitable waters. The greater attention now being given to home- (and Irish-) grown timbers is, however, likely to be fully justified.
M. L. ANDERSON

\title{
DRUG SUPPLIES DURING THE AMERICAN REVOLUTION
}

TNITIALLY, drug supplies for the American Revolutionary Army came from stocks largely in the hands of private druggists. This source of supply was totally inadequate for a war that attained such proportions as the Revolution. Even if stocks of drugs in the Colonies had been far greater than they were, there is little reason for believing that shortages would not have developed. Even the most patriotic pharmacists were faced with complete financial suicide, caught between a spiralling inflation and a Congress that had no money and only a promise for the future. In an interesting paper, George $\mathbf{B}$. Griffenhagen, formerly curator of medical sciences, U.S. National Museum, Smithsonian Institution (Bull. 225), shows how the internal organization of the medical department of the army was so chaotic that, even if adequate supplies were available and if the almost unsurmountable problems of communications and transportation had been solved, it is almost certain that shortages would have developed at least during the campaign of 1776.

The encouragement which Congress, through its Secret Committee, gave to private shippers for the importation of vital war supplies offered little relief in the field of medical supplies. Importation was cut off from Great Britain, and France did not directly export any quantities of medical supplies, at least until 1778. American privateers found it much more profitable to prey on British shipping than to develop trade channels with countries which, prior to the Revolution, were prohibited from shipping directly to the Colonies.

Hence, the most immediate relief from medical supply shortages was provided by the American privateers. Drug cargoes from British prize ships, many of which were en route to New York, served as a most important source of supply, particularly during 1777 and 1778.

The number of individual drugs mentioned in various inventories was considerable. Of these, only about a dozen were critically short. Heading the list of these 'capital articles' was Peruvian bark, the same cinchona from which quinine was later discovered. Tons of bark were used during the Revolutionary War, and the price more than quadrupled between June 1776 and September 1777.

The most prominent group of drugs on the list of capital articles consisted of cathartics and purgatives. Jalap, ipecac, and rhubarb were the botanical favourites, while bitter purging salt (Epsom salts) and Glauber's purging salts were the chemical choices for purging. Tartar emetic was the choice for a vomit, and cantharides (Spanish flies) was the most important ingredient for blistering plasters. Opium was administered for its narcotic effects, while gum camphor, nitre (saltpetre or potassium nitrate), and mercury (pure metal as well as certain salts) were employed for a variety of purposes. Lint, a form of absorbent material made by scraping or picking apart old woven material, was also in short supply.

Equipment shortages included surgical instruments and mortar, and pestles for pulverizing crude drugs. Glass vials for holding compounded medicines were also a supply problem, especially after essential drugs again became available. Some of the shortages were eased by local manufacture. Lint was produced in large quantities in the Colonies, and glass vials were manufactured in numerous glasshouses. Local manufacture of purging salts and nitre aided in eliminating shortages of these essential items, and, at the same time led to the first large-scale pharmaceutical manufacturing in the United States.

\section{$\pi$-ELECTRONIC EXCITATION AND IONIZATION ENERGIES OF CONDENSED RING AROMATIC HYDROCARBONS}

\author{
By DR. J. B. BIRKS and M. A. SLIFKIN \\ Physical Laboratories, University of Manchester
}

HE condensed ring aromatic hydrocarbons form
an interesting group of molecules. They possess
delocalized $\pi$-electron systems, loosely bound by a
potential defined by the shape of the planar molecular
skeleton; they scintillate, fluoresce and phosphoresce; some of the higher members are caroinogenic; and they possess certain well-defined electronic energylevels which vary systematically with molecular size. They have been the subject of many theoretical studies, including those based on the molecular 